\title{
Lessons Learned: 50 Years of Information Technology in the Banking Industry - The Example of Deutsche Bank AG
}

\author{
The article describes the development of information technology at Deutsche Bank as an \\ example for the banking industry. The authors discuss the effect of these developments \\ and ask where they come from. As a result, they obtain lessons learned from the last 50 \\ years. Based on these lessons an outlook on which might be the future drivers is given.
}

DOI 10.1007/s12599-008-0033-0

\section{The Authors \\ Hermann-Josef Lamberti \\ Member of the Management Board Deutsche Bank AG 60262 Frankfurt a.M. \\ Germany \\ hermann-josef.lamberti@db.com \\ Dr. Matthias Büger \\ Vice President Group Technology \& Operations \\ Deutsche Bank AG \\ 60262 Frankfurt a.M. \\ Germany \\ matthias.bueger@db.com}

Received: 2008-03-18

Accepted: 2008-07-31

Accepted after two revisions by Prof. Dr. Buhl.

This article is also available in German in print and via http://www.wirtschafts informatik.de: Lamberti HJ, Büger M (2008) Lessons learned: 50 Jahre Informationstechnologie im Bankgeschäft am Beispiel der Deutschen Bank AG. WIRTSCHAFTSINFORMATIK. doi: 10.1007/11576-008-0111-4.

\section{IT in the banking industry: rather a question of management than of technology}

Almost at the same time the first issue of the journal WIRTSCHAFTSINFORMATIK / Business \& Information Systems Engineering appeared, which was previously called elektronische datenverarbeitung (engl. electronic data processing), a newsletter of the Deutsche Bank headquarter was sent to its department managers with the following content:

"Due to taken samples we came to the belief that people prevalently act without second thought and that in most cases a telephone call or a telex is used for a specific issue instead of writing a short letter, which would be without any disadvantage. We cannot resist the impression that the appreciation for saving money, which had been a virtue in the banking industry in former times, disappeared more and more." (Historische Gesellschaft der Deutschen Bank e. V. 2005).

This passage does not only demonstrate the fundamental change in perspective that took place during the last 50 years. In the 1920s, the telephone entered business life; however, its impact on the banking industry was still not properly understood 30 years later. In this context one just has to think about stock broking which in its current form had only been enabled by real-time communication devices. This shows that using technology in business processes does not automatically result from its mere existence. Therefore it is necessary to know the possibilities of modern technology as well as one's own processes at the same time. This cannot be taken for granted as the excerpt from 1958 demonstrates.

The usage of information technology (IT) in the banking industry shows clear analogies to the telephone example. In the 1980s, a lot of bank managers still did not consider IT - or EDP (electronic data processing) as it had been called to that time as an integral part of their business. In this sense the words of Dr. Ulrich Weiss, management board member of Deutsche Bank, which appeared in the brochure "Our EDP - a concept with a bright future" (Weiss 1986a), were quite visionary:
"If the computer inherently belongs somewhere first of all, then it is the bank. For a company like Deutsche Bank with a continuously growing business volume, electronic data processing simply is a necessity."

This is not a matter of technology in the first place but a matter of realizing that - and of course how - the own business can be improved and advanced with the help of technology. A concrete reason for using technology in the banking industry usually was handling existing processes more efficiently. Interestingly, the technology originally seen as support also significantly contributed to questioning fundamental aspects of existing processes and, as a consequence, to changing the banking industry's core itself. As an example one can consider the terminal concept (realized by Dr. Weiss at Deutsche Bank; cf. chapter 3.2), which fundamentally changed the bank/customer interface and hence the banking industry. It was this interdependency of classical banking business and technology that sustainably changed the banking industry and probably will continue to change it in future as well.

In this paper we would like to present the interplay of banking business and (information) technology with Deutsche Bank as example and especially show the upheavals induced by technology. The article is structured according to the stages of development: from the beginning of information technology usage in the banking industry via the single steps of evolution up to the consequences of banking technology industrialization. Wherever it seems possible and appropriate, conclusions for the future are drawn from the past. 
The article is based on the archive of Deutsche Bank. We do not misconceive the differences within the financial industry, in an international comparison as well as within Germany - one just has to think of the three pillars of the German financial industry (savings banks, cooperative banks, and private banks). Nevertheless, we believe that the example of Deutsche Bank is quite prototypal for the interplay of information technology and the banking industry during the past 50 years and that the conclusions are not limited to single fields of financial industry. Based on this, the aim of this article is to gain insights from reviewing 50 years of information technology at Deutsche Bank which are as general as possible and helpful for facing future developments.

\section{The beginnings information technology usage in the banking industry}

For fulfilling their tasks banks have made use of the technology of their time ever since. Therefore, the relation between banking industry and technology in the $20^{\text {th }}$ century principally is not a new development. In Mesopotamia, where the first banks are assumed to be built in the $2^{\text {nd }}$ century B.C. that kept accounts for deposits and receivables, the first allocation and archiving techniques had already been used. Particularly terra cotta plates had been used. The introduction of coins followed the technical progress in metal processing. Paper-based documents that certified rights can be considered as a major innovation of the $17^{\text {th }}$ century. Bearer papers and unlimited fungibility constituted a quantum leap for the banking industry, which is ultimately connected to the Medici and the Fugger. This was also based on technological progress that enabled the production of paper-based documents with high quality (fraud resistance) in an adequate number and at justifiable cost.

Almost until the second half of the $20^{\text {th }}$ century accounts were still kept manually. To that time personnel cost grew significantly and a glance at the annual report of Deutsche Bank from 1924 shows that also the use of machines was supposed to be forced by this development:

"The payments to pay scale employees have been raised four times in the course of this reporting year. The total extent of

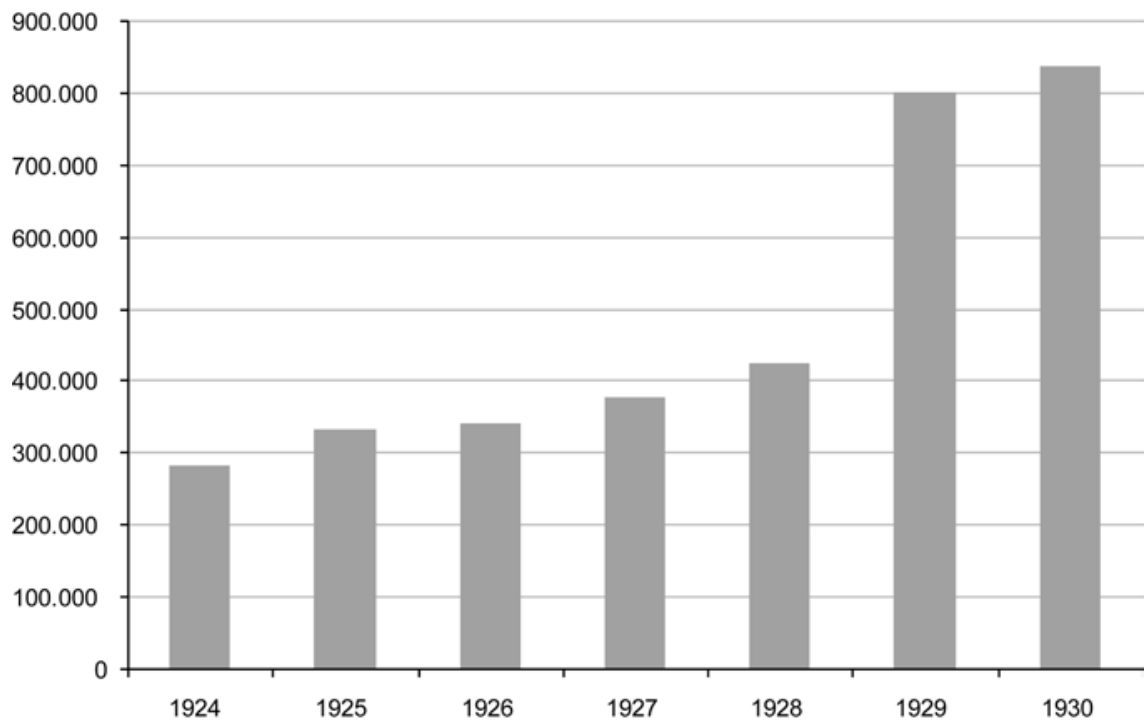

Fig. 1 Number of accounts kept at Deutsche Bank AG

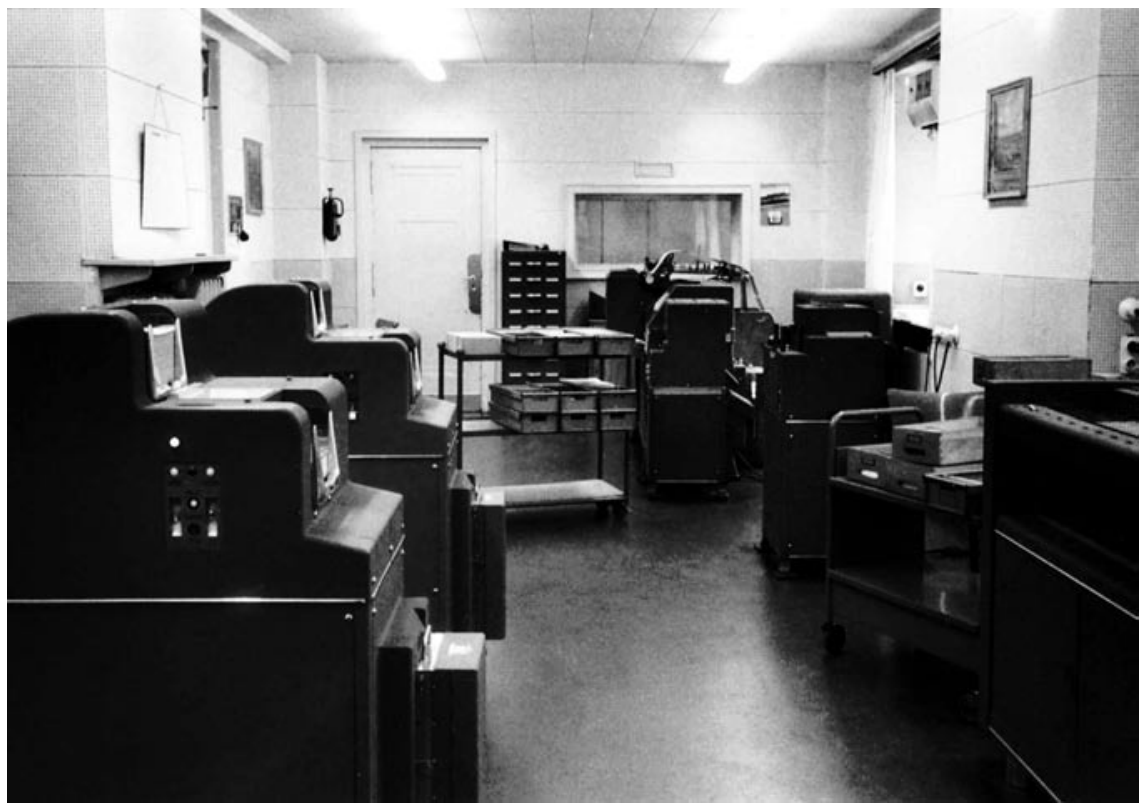

Fig. 2 Punch card department in Wuppertal of Deutsche Bank 1958

these raises alternated between 26 and $41 \%$ among the different groups and years of service, and arrived at approx. $31 \%$ in average. With the reduction [in staff] also the reduction of operating costs by means of introducing machines has to be further pursued." (Deutsche Bank AG 1925, p. 24)

Between 1924 and 1930 Deutsche Bank recorded a significant increase of its accounts (Fig. 1).

The reason for this development was the economic boom in the German Reich after the currency reorganization in 1932 on the one hand, and the merger with the Disconto-Gesellschaft in 1929 on the other hand. Therefore, it is obvious that the cost pressure on the one hand and increasing volumes on the other hand were the decisive reasons for the first use of punch card machines in 1928.

Machines were used that functioned according to the method of the inventor Herman Hollerith. Hollerith invented devices for an automated evaluation of the census in 1890 in the USA, and later founded the Tabulating Machine Company, which is in fact a predecessor company of IBM. There is evidence that these devices had been used in 1928 in a branch of the Disconto-Gesellschaft in Düsseldorf. However, the use of punch card 


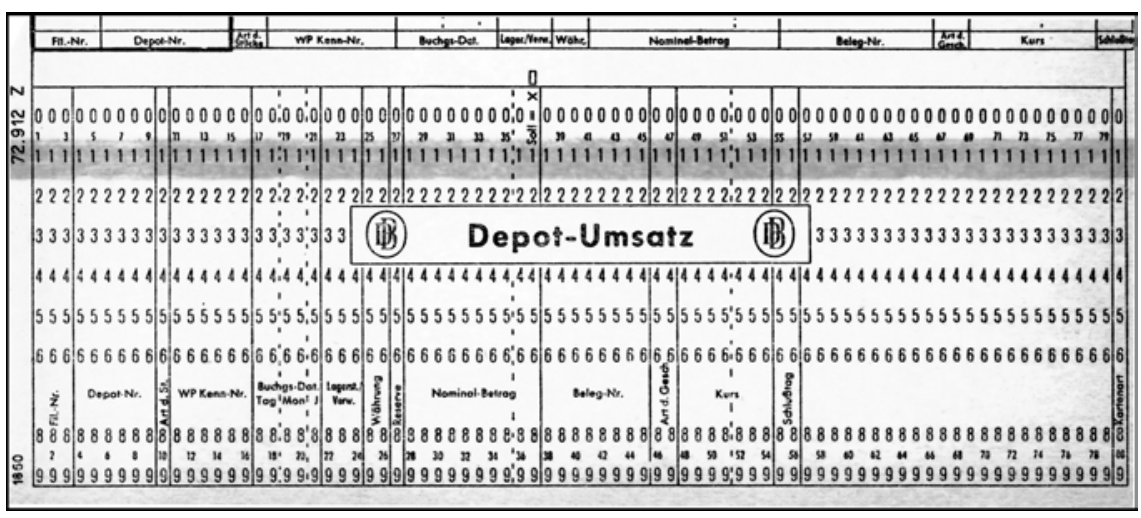

Fig. 3 Deutsche Bank, template of a deposit transaction via punch cards at the end of the 1950 s

machines - today we would probably talk about a pilot project - was not successful. No more branches had been equipped; even the branch in Düsseldorf had to quit using them.

The reasons for the failure in using information technology to the end of the 1920s are not recorded. This is even more regrettable because these reasons could have given information about the bank's processes and the difficulties of integrating new technology today. Thus, it can only be assumed that those reasons were decisive that had been mentioned as doubts within the second and henceforth successful attempt of introducing punch cards in the bank in 1954. Accordingly, the internal report of the organizational department of the Süddeutsche Bank (one of the predecessor institutes of Deutsche Bank) critically comments on the use of punch cards during a visit at a punch card system suppliers' delegation:

"Occasionally we asked at our visit how counseling of investment customers is handled without holding the deposit book in one's hands as we do. This question caused a long and embarrassing silence and after some deep thoughts they replied that they are able to create an overview of the single customer's deposit by means of the punch card system. However, after an in-depth conversation the result was that one definitely needs more than 15 minutes to do that, which is a period of time that even increases by $5 \mathrm{~min}$. to $20 \mathrm{~min}$. because of the distance between counter and Hollerith department. During that period our customer would have become very impatient of course, and a temperamental person would even talk of sloppy work. Then we only could give as an excuse that this delay was caused by modern punch card methods." (Historische Gesellschaft der Deutschen Bank e. V. 2005, p. 1)

This early example already shows that the actual challenge with using technology in the banking industry is its integration with business processes. Particularly interface deficiencies - here figuratively demonstrated by the distance between counter and Hollerith department - may completely annihilate the advantages of technology usage.

The expectation that it would be impossible to manage the future amount of work without punch card machines was crucial for the positive recommendation to management in the end. Therefore the question of scalability, which is the possibility of promptly processing a growing amount of data, played a major or even central role for using information technology in the banking industry right from the beginning.

Especially the predecessor institutes of Deutsche Bank in Hamburg and Düsseldorf had originally been open-minded towards the new technology. Nevertheless, the doubts of the Süddeutsche Bank from Munich cannot be denied: It is not a practicable way to change existing customer processes to the worse referring to new technology. If business processes are changed, they have to match or surpass the previous performance. The customer willingly accepts positive innovation (e. g., faster or cheaper processing) but is very rarely willing to accept restrictions of known functionality at the same time. This has to be taken into account especially when migrating to new IT systems. Therefore, banking technology can never be seen isolated to previously existing systems and processes.

In September 1955, the branch in Wuppertal of the Rheinisch Westfälische Bank started the application of punch card technology (Fig. 2). Previously, business processes had been analyzed precisely. Starting from the pilot branch, punch card machines had been introduced in the entire group of Deutsche Bank. In the case of the machines in Wuppertal they chose the French brand Compagnie des Machines Bull (which was taken over by General Electric in 1964). Besides IBM and Remington Rand this brand belonged to the three major providers of punch card technology in Germany.

The first business process supported by punch cards was processing current accounts. In this case loose account leaflets replaced the previously used account cards. They chose current accounts because their conversion was least complicated compared to other banking processes. The transformation had been completed after a period of six weeks. Afterwards currency accounts, bank and agency accounts, internal accounts up to general accounting and larger parts of cash transfer including standing orders followed.

Interestingly, there were no cost savings in the current accounts business despite automation of manual processes. The documents from the Süddeutsche Bank (having a skeptical attitude anyway) indicate that they had reports from a neighboring bank which could not attain a reduction of cost by changing current accounts to punch cards: According to these reports the saved personnel costs were totally compensated by higher material costs and depreciations for the comparably expensive machines.

This negative cost/benefit relation did not change until punch cards were also used in the deposit management (Fig. 3). In this case it was decisive that there were many automatable manual work processes for one and the same business transaction.

Then the result of using punch cards in the deposit management was positive as well. Thus, to the end of the year 1957 the deposit statements could be sent to the customers together with their balance of accounts. After one and a half year an interim result came to a "considerable cost reduction" (Historische Gesellschaft der Deutschen Bank e. V. 2005, p. 4). Another reason for the positive economical development was the improvement of process quality and the resulting decrease of complaints - additionally, the former inquiries that frequently came up in February or March in 
the case of still outstanding deposit statements did not occur anymore.

Especially because the value of technology is based on how it supports a business process, its use does only make sense if the business process can entirely be designed such that an advantage emerges. This can also be clearly demonstrated with the example of introducing punch cards: In 1928, punch card technology had a certain technical maturity - the first use of punch cards for mechanical control of looms (by Joseph-Marie Jacquard 1805 in Lyon) could be dated back 120 years after all. The business process itself had not been developed as far as punch cards could have generated value by supporting it.

Therefore, major drivers of development are higher requirements, e. g. growing volumes that cannot be handled without new technology. Such reasons finally also caused the introduction of punch cards in the 1950s. As soon as the technology has been completely introduced, the newly developed system landscape provides the prerequisites for new processes. Subsequently, a pressure emerges that leads up to the development of technical standards to enable interoperability of the independently developed systems.

\section{Lessons learned:}

In this early stage of information technology usage in the banking industry some fundamental principles already become obvious that are still valid today:

1. Technology has to excel in use for the customers. Customers will not accept change for the worse.

2. Information technology usage has to support business processes. Therefore, selecting and designing the right process are central prerequisites for the (economic) success of technology usage.

3. Prioritization has to be accomplished according to the economic potential of business processes and should not predominately be focused on the simplicity of technical realization.

4. Cost reduction resulting from using new technology can usually be realized in the long term only, especially in the case of larger investments.

5. Technology usage is often driven by higher requirements, e. g. growing volumes that could not have been handled without new technology.

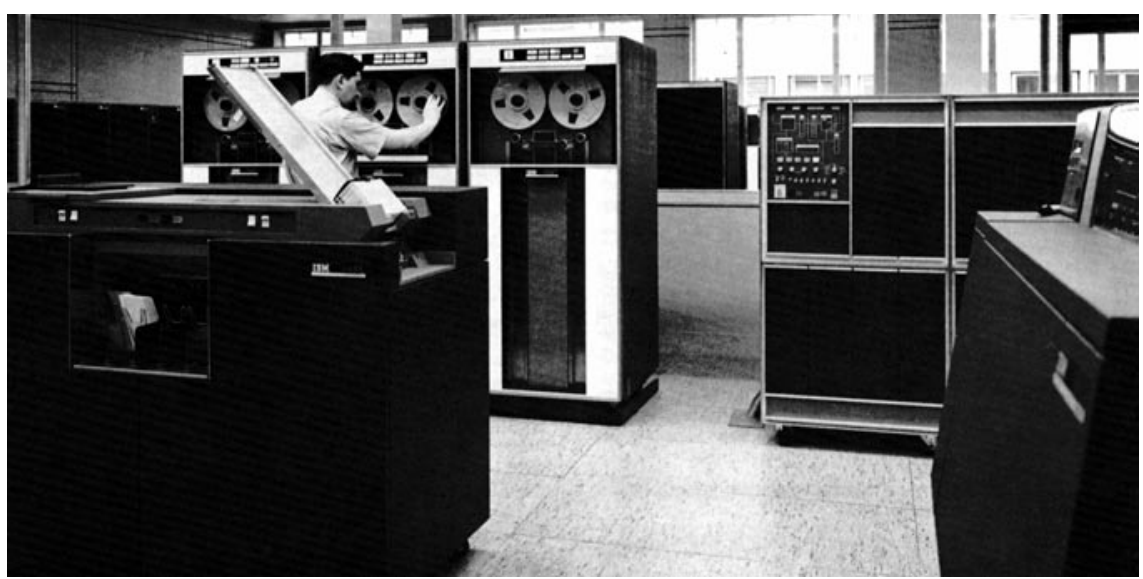

Fig. 4 Deutsche Bank, system IBM 1401

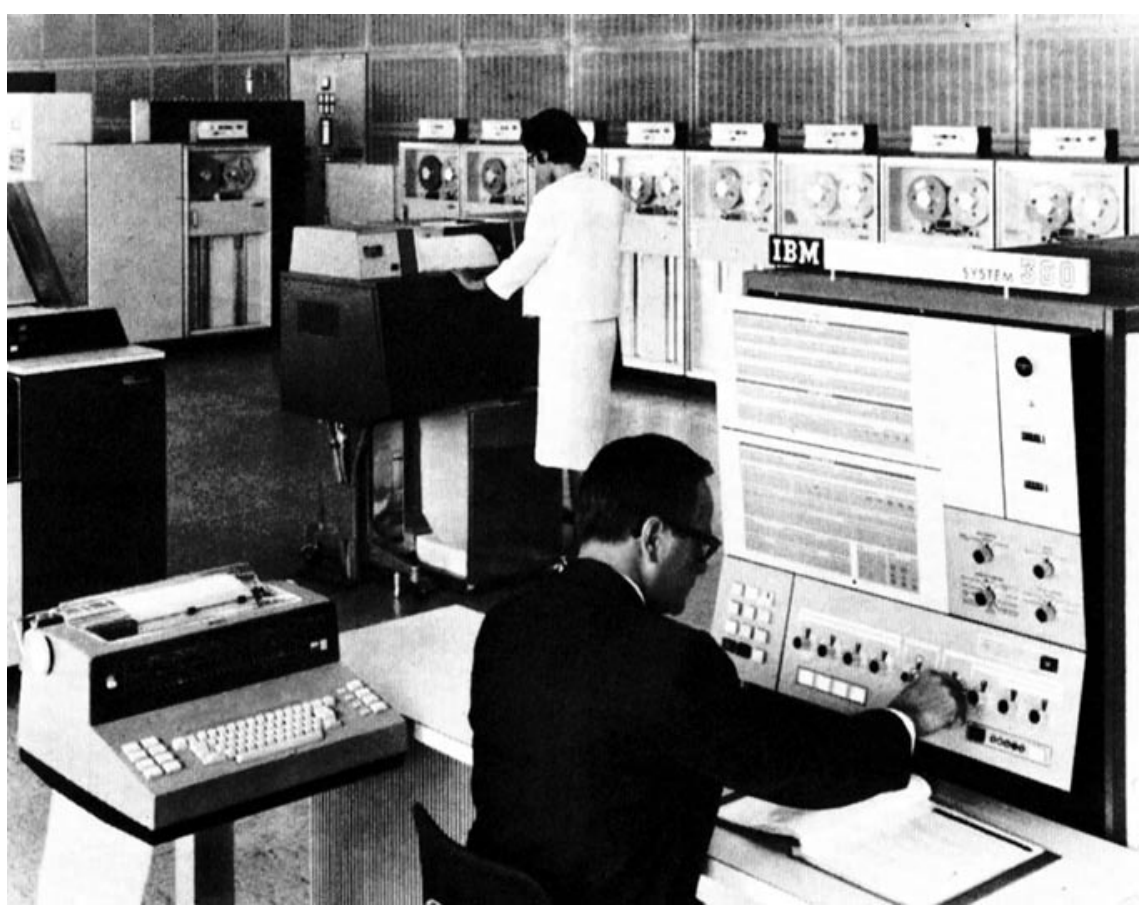

Fig. 5 IBM /360 systems in use at Deutsche Bank

\section{Development by leaps}

\subsection{Magnetic tapes and integrated data processing}

The era of punch card machines at Deutsche Bank ended at the beginning of the 1960s with the introduction of new systems that used magnetic tapes as data storage mediums. In February 1962, Hamburg was the first branch to be equipped with an IBM system type 1401. Until 1964 almost all main branches had been equipped by similar systems (Fig. 4).

The major reason for the technical reorganization was that punch card machines met their limits while processing the increased business volumes. Thus, in an internal publication of Deutsche Bank
AG Horstmann (1969) explains the situation before the introduction of the new electron tube-based machines as follows: "In each business sector, such as current accounts, savings-, deposit- or personal loan-business, annual growth rates of 15 to $20 \%$ had almost been standard. The stock of punch cards to be maintained in larger branches reached one million. Further installations of tabulating machines were not economical and caused problems due to spatial and personnel reasons."

By using IBM 1401 systems, which stored their data on magnetic tapes instead of punch cards, it was possible to raise processing speeds significantly and above all to better cope with peak loads. The old punch card systems required 36 hours for the 17,000 regular orders that had to be 


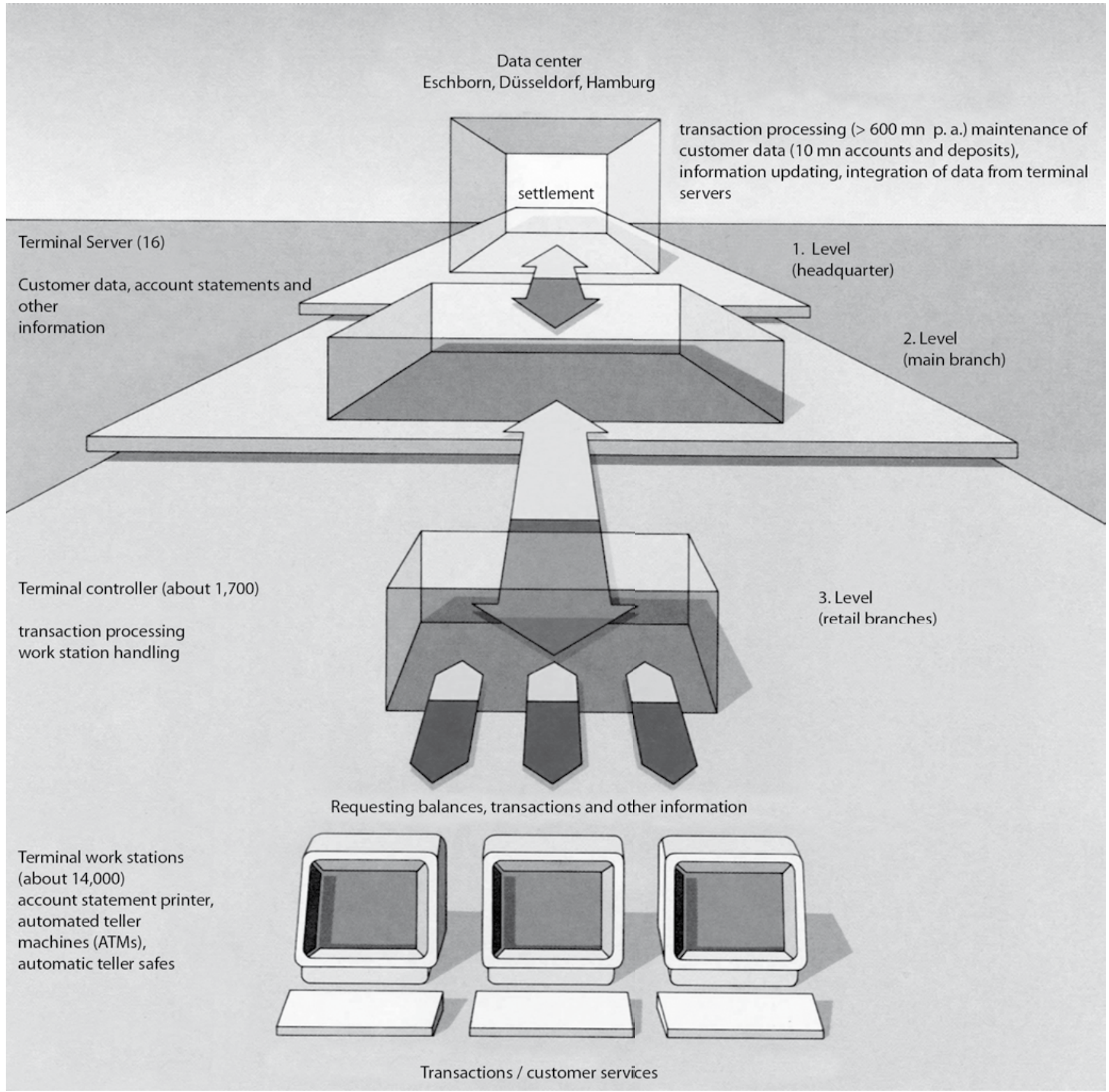

Fig. 6 Second phase of the terminal concept at Deutsche Bank (Deutsche Bank AG 1986)

carried out in one main branch at the first day of the month whereas the new IBM 1401 systems were able to process the same amount in less than 9 hours (Horstmann 1969, p. 10).

Despite this improvement regarding performance the new systems already met their limits again four years later. Consequently, as from 1966 the third generation of IT systems at Deutsche Bank was introduced in the shape of IBM 360 (especially IBM 360/30, 360/40, and 360/50, Fig. 5) and Siemens 4004 computers. The reason for the increased demand can also be seen in centralization especially of the deposit and credit business to a small amount of data centers.

Besides higher processing speeds the internal report also mentions higher flexibility as another advantage resulting from programmability. However, reducing transaction costs had not been the primary aim of the second phase of technological development either - thus in the context of IBM 1401 systems the internal report also talks about "relatively expensive machines" and does not indicate any concrete cost reduction aims.
Moreover, another major progress compared to punch card machines was the fact that "data which is once attained in an EDP system can be reused directly from the system without reproduction" a characteristic which Horstmann (1969) called "integrated data processing". The fact that the result of an operation was at the same time the input of another operation was a fundamental advancement. Among other things it allowed for analyzing large amounts of data systematically in consideration of different aspects. Statistical data in particular could be interpreted 
automatically for the first time without any additional costs worth mentioning and (almost) real-time.

It is remarkable that this functionality of analyzing statistical data, which had already been noted to be very important in 1969, originally was not the focus of consideration and was not crucial for the decision of using IBM 1401 systems. The necessity of processing large transaction units led to using new technology which allowed surpassing its original purpose. Recognizing this additional functionality and its value for the banking industry was innovative. The implementation was accelerated because nearly no additional costs incurred for using the new functionality. After having recognized the value of statistical reports the demand for these reports escalated, which again led to new system requirements. Meaningful statistical data improved the basis for decisionmaking and thus became a competitive advantage in actual banking business.

The example of statistical reports is interesting and prototypal because it is an early example showing what kind of effect innovative use of technology has on the banking business, how it generates new demand, and finally changes banking itself.

\subsection{The introduction of banking terminals}

Until the 1970s, banks used technology for back-office data processing only. The introduction of banking terminals, especially of statement printers and cash terminals at the beginning of the 1980s was a quantum leap in information technology usage in the banking industry. For the first time customers directly interacted with the technical devices of the bank - without the bank employee working as an intermediary.

At Deutsche Bank the era of banking terminals started in 1974. From 1977 on, terminals had exhaustively been set up directly at the counters. They allowed for automatic input of in- and outgoing payments to savings books, a process that had to be done manually before. As regards stock broking, orders could be accepted and forwarded directly. In this way banking technology came within sight for the customer for the first time and was perceived as such.

By enabling the second phase of the terminal concept (Fig.6), which we would call a (multilevel) client-server-concept in

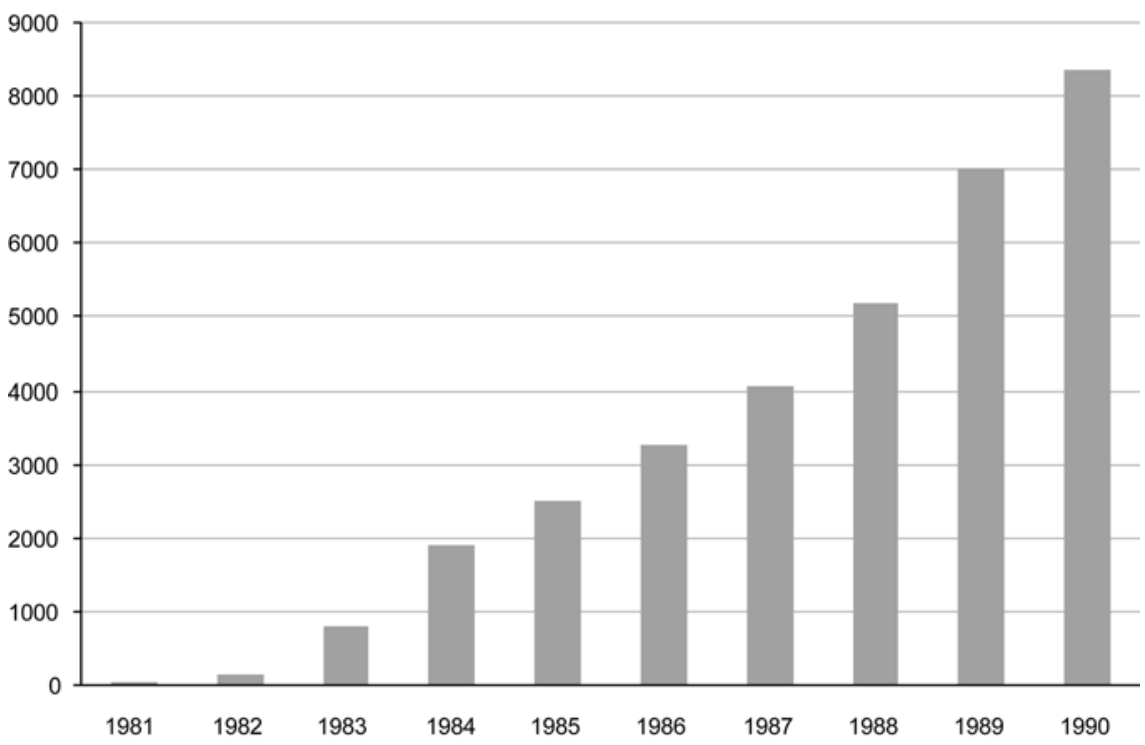

Fig. 7 Number of cash terminals in the Federal Republic of Germany in the 1980s

today's terminology, the bank entered new technological territory.

16 regional data centers in the main branches as well as the large-scale data center with operating sites in Eschborn, Düsseldorf, and Hamburg can be considered as the heart of the bank's terminal concept. More than 14,000 terminals in the branches had been connected to these data centers. The mainframe computers, which had been used since 1979, were of the IBM 3033 type and simultaneously replaced the previously used Siemens computers. By the end of the 1970s, 2.9 million current accounts and 5.8 million savings accounts were managed in that way. In 1982 a repeated renewal of the terminal systems took place which caused the acquisition of approx. 30,000 terminals for 20,000 users in 1,200 branches. In this phase devices from different providers, in particular IBM, Siemens, and Nixdorf, were used.

However, using devices of three different providers, which was also for business policy reasons, caused higher complexity: Each device had to be programmed by the provider with a unique assemblerlike machine language. There were neither standard routines nor standard interfaces. Though, the aim of the terminal concept was to build up a modular system - in an internal publication (Deutsche Bank AG 1986) this has been called an "Add-on system" - in which individual "units can be changed, modernized, or supplemented if required". This required a step of standardization which anticipates ideas of the "industrialization" carried out today.
The bank decided to develop a meta-language and to define so-called masks on their basis. One element of this meta-language was the command "print savings book" for instance. These masks were small programs written in this meta-language that were able to implement single business processes and business process activities respectively. Then the bank requested of the three providers to develop an interpreter so that the masks could be processed independently of the particular device. In that way the bank was independent of the individual providers even without standardization of IT that had not happened so far and without increasing complexity of its own IT landscape.

Though being a proprietary system, the masks concept was so successful in the end that a lot of masks were still productive in 2000. Its principles also had to be taken into account for the renewal of the branch infrastructure within the project "eBranch" (see chapter 3.4).

Moreover, it was new that the internal publication (Deutsche Bank AG 1986) considered the terminal concept, which is an aspect of banking technology, as "strategic instrument", "in order to faster discover market opportunities and to seize them subsequently to efficiently control cost that is related to preparing and realizing selling activities”. Furthermore one has to know that installing and technically connecting statement printers, cash terminals, and automatic cash safes, which revolutionized the routine business in the bank's branches in the 1980s and 1990s, was an integrated part of the 


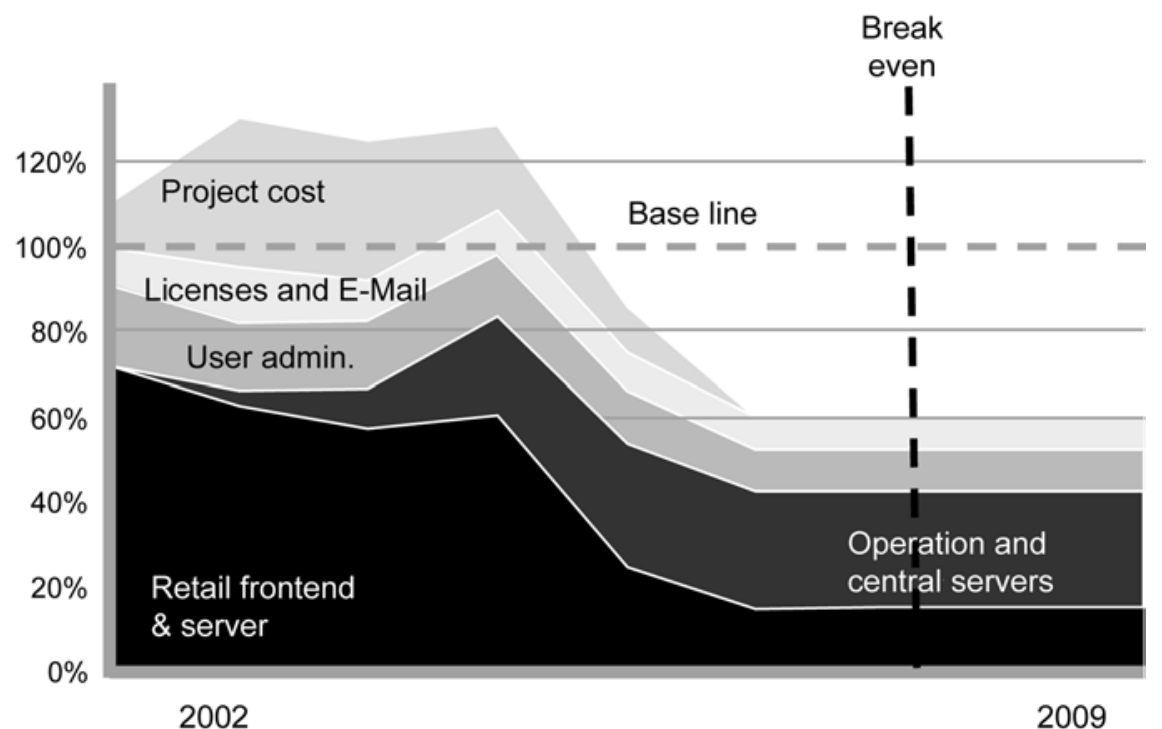

Fig. 8 Costs of the branch infrastructure after the eBranch project

terminal concept because customers now directly interacted with the bank's technical devices.

The development's dynamics can be described best by having a look at the development of cash terminals (Fig. 7). Although being exotic at the beginning of the 1980s - in 1981 there had only been 22 cash terminals in use - the number of suchlike machines increased to more than 8,000 at the end of the decade. In the 1990s (in the reunited Germany) another increase to approx. 47,000 took place. In an almost saturated market we now count approx. 53,000 cash terminals in Germany.

The biggest challenge of using cash terminals was neither the technology - functioning devices had already been available from the beginning of the 1970s - nor security-related aspects but the required change in customer behavior. Up to the 1980s, customers were not used to work with technical devices - even for mere routine issues such as drawing cash. Already in 1981 the group manager of Deutsche Bank Dr. Weiss described the central role of marketing as follows:

"Therefore marketing plays a major role for the adequate use of self-service facilities. For instance, assuming that the major benefit - e. g. of cash terminals - does not consist of improving customer services but rather of the economy of scale, one corresponds to the economization's aim best by using devices that are set up in the service hall or vestibule for relieving the cashier. Marketing has to help 'educating' customers for using these devices." (Weiss 1981)
The success of cash terminals caused in the middle of the 1980 s can be traced back to a number of reasons of which higher availability (cash output outside the opening hours) is of decisive importance. Moreover, the growing understanding regarding information technology due to the increasing distribution of home computers had a positive effect, too.

This development had a positive impact on the banking industry on the one hand because it relieved the branch employees from routine tasks and thus contributed to cost reductions in the long run. On the other hand, the growing use of technology caused the risk of anonymization and thus decreasing customer loyalty which became an important issue. The central question was not how such terminals could be technically integrated in the bank, but a rather business policy-related question on which tasks the banking terminals were supposed to cover. In a presentation on "Problems and limits of technology" from 1981, Dr. Weiss already pointed out the central challenge of using technology as regards private banking customers:

"What we are dealing with is the decision on which tasks carried out by our employees so far - predominantly concerning monetary transactions - can be expected to be carried out by customers using a self-service terminal. A bank has customer service standard by exorbitant automation. On the other hand, automation offers the opportunity to improve the terminal's counseling quality and above all to use employees that have been relieved to pay attention to not losing its individual from routine tasks for qualified customer advisory services." (Weiss 1982)

25 years later we know that information technology indeed enables to offer individual services. However, another important fact is that the bank management is not supposed to predominantly think about how to implement or manage technology. Instead it should make sure that the prerequisites are fulfilled so that new technological developments generate value in the banking business. Among this are the analysis of customer approval, the alignment with the business model, and the question on how a bank's processes change due to technology usage. Thus, an elaborate IT-strategy is necessary for all aspects of modern banking business (see also Lamberti 2006).

\subsection{Equipping branches with PCs - the "new operative systems"}

Due to restrictions in functionality for new applications, the terminal concept of the 1980s was not sufficient anymore in the 1990s. The former performance capacities did not suffice to manage the infrastructure with terminals of larger functional volume from central data centers. Therefore, Deutsche Bank decided to introduce the so-called 'New operative system' (NOS) in 1996. In the course of this, all branches had been equipped with powerful PCs and a new network (Open User System - OPUS) as well as a management information system (MIS) had been established.

The employee magazine Forum (Deutsche Bank AG 1986) reported on the upcoming modifications as follows:

"Within two years 1,600 branches are supposed to be changed over. Among other things this means an installation of 70,000 sockets, laying 5,000 kilometers of copper cable, setting up 35,000 end user devices and the training of approx. 40,000 employees nationwide."

This report shows that NOS caused a fundamental infrastructure development - leading up to power supply. Together with NOS the majority of bank employees gained access to a computer that was integrated in the company's network. Thus, NOS was the necessary prerequisite for the standard use of PCs as a central working device in everyday office life: the use of wordprocessing, spreadsheet analysis, and other standard tools. This demanded a significant change-over of the employ- 
ees, especially of those who had not been working with a PC in their private or professional environment so far. Therefore, besides extensive training a lot of events took place where people presented the advantages of the new working equipment to the employees.

The fact that the approval of new technologies occasionally depends on unusual factors can be seen by considering the example of e-mail. The first e-mail systems had already been used before the new operative systems had been introduced. As a rule, employees preferred communicating by phone or fax which they were already used to. After the German reunification in 1990, when the phone network was not powerful enough to cross the former frontier, e-mail became the only reliable way of communication between places in the new and old federal states. This was because the (internal) data network had no performance problems. This was the breakthrough of e-mail as an inhouse communication channel: The bank employees who had been convinced of the technology's advantages in that way increasingly went on using e-mail even to that point when the new phone lines had been installed long before.

\subsection{Thin-client-architecture: eBranch}

Around the turn of the millennium discussions about a fundamental changeover of the system landscape in the branches arose. Decentralized servers in the branches had proved to cause high maintenance efforts and raised the complexity of the system as a whole. At the same time, the newly available network capacities again allowed for real-time connections between the branches and central data centers.

The core of the eBranch project consisted of replacing the former OS/2-landscape by modern Citrix terminal-server technology. At the same time 1,300 decentralized servers had been replaced by only 20 centralized server stations. The connection of thin clients to these central processing units was preferred but also PCs, mobile end-user devices, printers, and other end-user devices had been connected. The change-over of the branch infrastructure was a project of enormous extent, especially since daily business had to be completely sustained during the period of reorganization.

As a consequence of the change-over, current costs of the branch infrastructure could be reduced by one third compared to the former "OS/2" cost base (Fig. 8). This cost reduction can basically be traced back to a lower degree of complexity and the resulting lower maintenance costs.

\section{Lessons learned:}

6. The development of using technology in the bank is not a continuous process but a process by leaps.

7. The opportunities enabled by information technology have an immediate effect on the bank's organizational structure. In this way, e. g., the relation of available bandwidth and computing performance directly influences the question on whether the branches can be connected to central servers or not.

\section{Industrialization of banking technology}

The use of IT in the banking industry was carried out in the first step by the acquisition of hardware - from the punch card machines mentioned above up to more powerful computers. In that way banks became owners and users of data centers. The reason can be seen in the providers' business model that focused on selling hardware and left the development of software to the user. This fact led to individual and hardly standardized system landscapes in which the bank was at the same time hardware owner and developer of the employed software. This state lasted a long time, especially since processes and applications had not been standardized. This still affected the entire range of software during the 1950s and 1960s; only afterwards standardized products could be used but still had to be customized to the bank's requirements very often.

Industrialization of information technology, marked by broad standardization and an extensive offer of external service providers with specialized knowhow, provided the banking industry with the opportunity to break up these structures and to buy, besides hardware, also software and even complete business processes. This paradigm shift has shaped the banking industry since the beginning of the new millennium.

A necessary requirement for industrialization of the banking industry is a standardization of IT-supported banking pro-

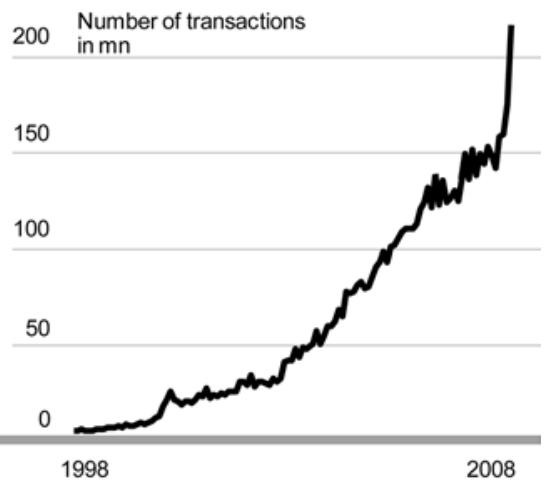

Fig. 9 Number of online banking transactions of Deutsche Bank per month

cesses including all business and supporting processes. Standardization is meant to cover all phases within the production of goods and services. The production process is then split up into single components (modules). Without standardization and modularization it would not be possible for any supplier to offer the same component to a large number of financial institutions. However, this is a necessary condition for a functional market and for achieving economies of scale on the part of the supplier.

Consequently, the issue of outsourcing IT-processes at Deutsche Bank gained an increasing attention. Partial outsourcing of software development to Bangalore (India) was pioneering. Therefore, DSL as a $100 \%$ subsidiary was founded in 1992 (the name DSL originally meant "Deutsche Software Limited", whereas later the company operated under the name "DSL Software Limited"). After a period of process consolidation in the second half of the 1990s the bank gradually retired from its function as an owner between 2001 and 2004. Further prominent projects were the outsourcing of desktop services to Siemens (2001/02), the domestic payment transactions to Postbank (2004), and the continental European data center to IBM (2002/03).

The industrialization of IT additionally enables the bank to choose between handling IT-supported processes on its own or procuring them from external partners. The decision mainly depends on the role of IT for the particular banking product. If it is a mass product (commodity) where differentiation only results from pricing, outsourcing of the appropriate IT-process is much easier than in cases of new banking products which are enabled only by innovative IT-solutions (enabler). In 


\section{Frankfurt monthly average cash market order book volume (EUR bn)}

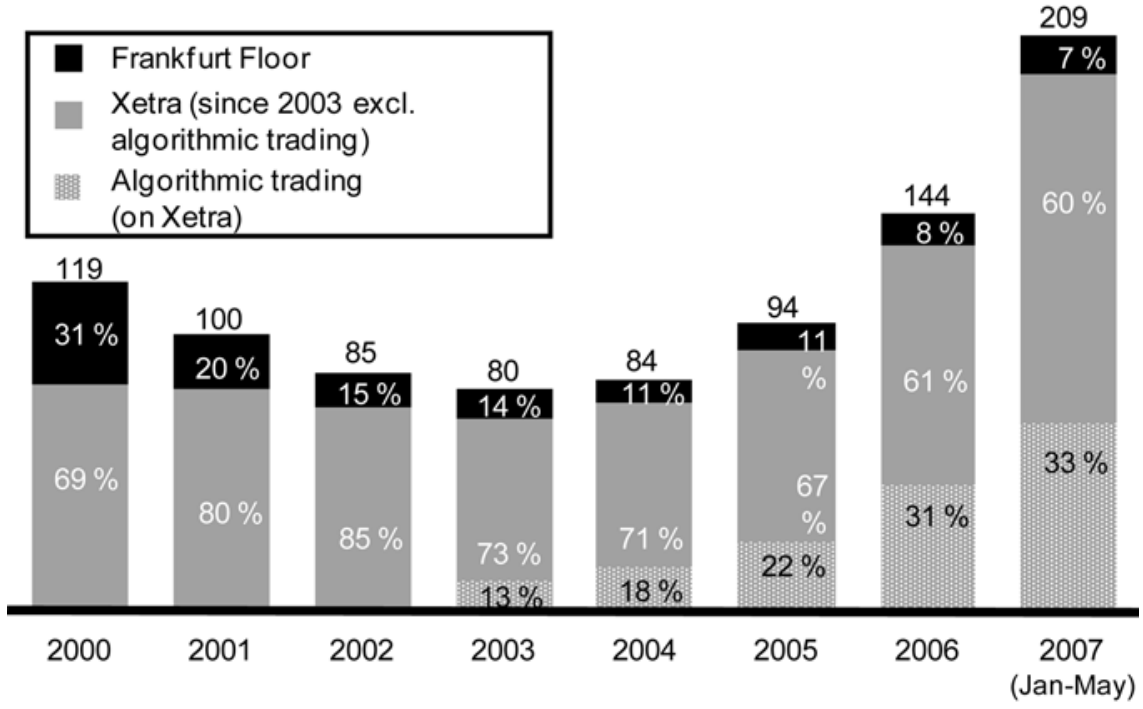

Fig. 10 Development of the order volume at the German stock-market in Frankfurt according to Deutsche Börse $(2007$, p. 18)

this respect a decision regarding partial outsourcing of a process always is a decision for business policy reasons as well. In future, the question on whether and to what extent outsourcing of IT-services is successful will be a major factor for the economic success of (transaction) banks, in particular in the case of mass software (commodities).

\section{Lessons learned:}

8. It may be expected that the trend of industrialization in financial industry will still last a while. It is strongly connected to the developments in the IT industry. There, great progress has been achieved as regards standardization and modularization during the last few years. IT service providers increasingly offer complete services to banks - a trend that will probably grow in intensity within the next years.

\section{Technology changes the banking industry}

The primary aim using technology in the banking industry was and still is to be able to manage growing business volumes. Realization of cost reduction due to automation and increasing efficiency definitely existed as an objective but initially was of a medium to long term perspective.

However, the impact of technology on the banking industry itself had been totally underestimated. Technology did not stay a support to existing processes but lead to a fundamental change of these processes themselves. Increasingly improved technology made bank employees dispensable as intermediaries between customers and technology - one just has to think of the previously mentioned upcoming of banking terminals in the 1980s and 1990s. Dr. Ulrich Weiss already recognized that this might have a considerable effect on the relation between banks and customers being important for their business relation. In an external publication Weiss (1986b) wrote:

"With all the technology, all rationalizing, the relation between customers and bank employees will always be at the center of all banking business efforts. [...] The customer consultant is increasingly relieved of routine processes by EDP and thus is enabled to face customers in personal contact to a greater extent and to counter anonymization."

In the same year Weiss (1986a) asked even stronger in an internal publication with the headline: "It is still valid: People shape the face of the bank":

"Is this the bank of our future? The customer enters a branch but does not see a friendly face, does not hear a friendly 'What can I do for you, Mr. Gruber?'. No, he stands in front of a number of monitors and keyboards and is informed about his current state of account by the statement printer, types his bank transfers next door, and finally gets cash from the bank termi- nal with his plastic card. Nobody is there to ask for advice or provide information."

This twenty years old description corresponds astonishingly well to our reality today, especially if one enters the self-service area outside a bank's opening hours. On the side of the bank this means efficiency and relief of routine tasks, on the side of the customer this means improved availability but also the anonymization of the bank-customer-relation as mentioned by Weiss. This even increased in the 1990s due to the introduction of online banking (Fig. 9).

Whereas even within the use of banking terminals the spatial closeness to the customer played a major role in classical banking business, each bank is just "as far away as a click" in the Internet. Direct banks take advantage of this fact and completely do without a branch network to reduce costs. The fact that this total mechanization and anonymization of the bank/customer relation only appeals to a limited potential customer base in reality and that good counseling still has its value is an observation which definitely will last in future, too - regardless of the fact that intelligent systems will fulfill more and more counseling functions. On the other hand no bank is able to persist today without offering technical solutions such as banking terminals or online banking. The quality of technical solutions even becomes a differentiating factor.

A consequence of using technology is that the financial institutions compete with each other in an unprecedented manner. The Internet almost completely removed the frequently existing information asymmetry of former times, a comparison of the different institutions' conditions is possible without difficulty - a transaction in the same way, even if the institution has no local branch. Regional principles become less important, more and more Germans have business relations to other banks in addition to their local bank.

This development would be unimaginable without modern information technology. Technology even allows for even further developments: Just as the distribution of information or selling of goods global networking could question the intermediary function of banks ("eBay-effect"). There are already the first platforms in Great Britain where debtors and creditors come together and arrange loans without intervention of a bank. If these loan auctions are able to reach a significant mar- 
ket share can hardly be estimated today. Though, it is sure that in line with the growing technical possibilities future business models in finance industry will be influenced by the state of the art of information technology with an upward tendency.

The use of IT in stock broking significantly changed the financial market during the last few years. This can clearly be seen by having a look at the order volumes of the German stock market in Frankfurt (Fig. 10).

Thus, the percentage of classical floor trading decreased to below $10 \%$ despite a collective growth in volume, whereas today more than $90 \%$ of the order volume is handled via the electronic trading platform Xetra. This influences the IT-systems in banks. They have to deal with growing volumes whereas response times in electronic business become more and more important. This makes great demands on scalability, speed, and stability of technical systems.

However, IT had another influence on business at the stock markets. Upcoming algorithmic trading, where single transactions are initiated according to predefined rules (algorithms) and not by a person, marks a fundamental change. The technical system is not only used to support the trader but even becomes a market participant itself. Algorithmic trading not only offers the possibility to automatically pursue a complex investment strategy. It even enables banks to offer new products, such as certificates for instance, to their customers, to offer real time information on market prices via their own platforms - the platform X-markets in case of Deutsche Bank, and to buy and sell the underlying stocks (or respective derivates) automatically at the stock market. The increased share of algorithmic trading - between 20 and $40 \%$ of the turnovers at most of the stock markets with an upward tendency shows the impact of this segment.

To sum up one can conclude: IT in the bank does not only mean implementing technical solutions for existing processes but also rethinking one's own processes and business models in the mirror of technological development. Therefore, dealing with technology is not (only) a task of the IT department but rather of the management - borders between IT and business disappear.

\section{Lessons learned:}

9. Technology does not only support existing business processes but increasingly constitutes a driver for changes within the actual banking business.

\section{Outlook}

What will the relation between information technology and banking industry look like in future? Thinking of the fact that technological leaps such as the development of PCs, calculating capacity, and the Internet as a global information platform had hardly been predictable, future prospects are rather difficult. It can be expected that there will be technological leaps in future which will influence banking technology significantly. The order or magnitude of these future leaps is hardly predictable.

However, an important finding from the past seems to be the fact that there is an increasing dependency between banking business and the developments in information technology. Keeping in mind that a bank mainly processes and exchanges data with its customers, it becomes clear that this relation will be even closer in future. This is not in opposition to the industrialization of the banking IT either. The more technically mature the IT industry becomes the easier it is to break up the supply chain, which means the easier it is to include suppliers. This will lead to the fact that standard services, which are not relevant for competition, will be sourced out to a greater extent. Times in which banking IT was carried out internally to $100 \%$ are irrecoverable.

Banking business and technology will merge together more and more, especially because technology creates new possibilities that enable business policy-related opportunities and because requirements of the business units will have more and more technical consequences. Innovation and finally economic success in the banking industry will consist of the symbiosis between banking business and technology.

The fact that the bank will become superfluous and might be replaced by a supplier of technological services hardly seems to be realistic. Economic core tasks of the banks are defined too clearly, especially risk and term transformations. As regards the handling of payment transactions, transaction banks might increas-

\section{Abstract}

Hermann-Josef Lamberti, Matthias Büger

\section{Lessons Learned: 50 Years of Information Technology in the Banking Industry - The Example of Deutsche Bank AG}

Based on the lessons learned from the last 50 years, statements are derived of which the authors claim that these will continue to be valid in future: Information technology in the banking industry supports business processes - selecting and designing processes will continue to decide about economic success in future. The necessity of handling a growing business volume will still be the major driver for using new information technology in the banking industry. It will be even more important than the aim of reducing costs by automation. Industrialization of IT will also change the use of technology in the banking industry. Hence, banks do not necessarily have to run their systems alone but may outsource services if required. The definition of the major business fields will significantly influence the banks' IT strategy and, among other factors, will decide on the market success of a bank. Technological development will have an increasing effect on the banking business, will change it, and enable new business models. Successfully dealing with technology-induced changes predominantly depends on a company's employees.

Keywords: Role of information technology in banking, Historical treatment, Change in banking IT 
ingly change to factories where machines are computers and their in- and output is data.

Otherwise there is nothing to be said against the fact that the major trends of the last 50 years can be extrapolated in future, too, and - this is our hypothesis - that the following main issues continue to be valid:

- The goal of information technology in banking is to support business processes - selecting and designing of processes will continue to decide about economic success in future.

- The necessity of handling a growing business volume will still be the major driver for using new information technology in the banking industry. It will be even more important than the aim of reducing costs by automation.

- Industrialization of IT will also change the use of technology in the banking industry. Here, a supply industry will develop. The definition of the major business fields will significantly influence the banks' IT strategy and, among other factors, will decide on the market success of a bank.

- Technological development will have an increasing effect on the banking business, will change it, and enable new business models.

The challenge will be to face permanent change and to make use of new technological possibilities for business by means of innovation. For this purpose management and employees are needed. Therefore, the sentence formulated by Weiss (1986a, p. 3) will still be valid in future:

"The quality of the bank will never result from technology alone but from the capability of its employees to efficiently use technology."

\section{Lessons learned:}

10. Successfully dealing with technology-induced changes predominantly depends on a company's employees.

\section{References}

Deutsche Bank AG (1925) Geschäftsbericht für das Jahr 1924

Deutsche Bank AG (1986) Unsere EDV - ein Konzept mit Zukunft. Internal Publication Deutsche Bank AG

Deutsche Bank AG (1996) Fit für die Zukunft: NOS startet in Saarbrücken. Forum (employee magazine of Deutsche Bank) (2). Internal Publication Deutsche Bank AG
Deutsche Börse (2007) Deutsche Börse Investor Day 2007, Frankfurt, 2007-06-22

Historische Gesellschaft der Deutschen Bank e. V. (2005) Fünfzig Jahre Elektronische Datenverarbeitung in der Deutschen Bank. Bank und Geschichte: Historische Rundschau (9)

Horstmann (1969) Automatische Datenverarbeitung - von einem Mitarbeiter verständlich gemacht. Internal Publication Deutsche Bank AG Lamberti HJ (2006) Bank und Technik: The perfect match. Bank und Markt (6):19f

Weiss U (1981) Bankstrategien für die achtziger Jahre. Bank und Markt (6)

Weiss U (1982) Probleme und Grenzen der Technik. Extract taken from a speech held at "Systems $81{ }^{\prime \prime}$ in Munich, 1981-10-19. Zeitschrift für das gesamte Kreditwesen (2)

Weiss U (1986a) Unsere EDV - ein Konzept mit Zukunft. Internal Publication Deutsche Bank AG

Weiss U (1986b) Bankdienstleistungen im Wandel. IHK magazin, Wirtschaftsinformationen der Industrie- und Handelskammer für die Pfalz/Ludwigshafen (9) 